\title{
IMPROVING UNDERSTANDING OF PRE-SERVICE TEACHER EXPERIENCE WITH TECHNOLOGY INTEGRATION
}

\author{
Dana Ruggiero $^{1}$ and Christopher Mong ${ }^{2}$ \\ ${ }^{1}$ School of Education, Bath Spa University, Bath, UK \\ ${ }^{2}$ Curriculum and Instruction, Purdue University, IN, USA
}

\begin{abstract}
Pre-service teachers develop technology competency during their tenure in the college classroom. These stages coincide with Bloom's Revised Taxonomy and offer the opportunity to learn and model technology integration. 656 pre-service education students from five universities across the United States completed a qualitative survey aimed at identifying how they perceived technology integration throughout their teacher education program. Three themes, corresponding to Bloom's Revised Taxonomy, were identified; 1) preservice teachers first identify and understand technology as a tool, 2) pre-service teachers apply technology and analyze the process of integration, and 3) overall, pre-service teachers do not evaluate and create technology integration experiences. The results of this study are discussed thematically in relation to Bloom's revised taxonomy. Limitations are discussed and recommendations for future research examined for pre-service teacher technology training.
\end{abstract}

\section{KEYWORDS}

Technology Integration, Multimedia, Teacher Education, Bloom's Taxonomy

\section{INTRODUCTION}

It has been well established that technology, like any other classroom advancement, is not a panacea for improving instruction [1,2]. Within the classroom, an instructor must be able to leverage not only technical knowledge, but also content knowledge and pedagogical knowledge in order to consistently create effective and efficient lessons [3]. A deficiency in any one of these areas can lead to failure, yet content and pedagogical knowledge are often the consistent focus of many teacher education programs [4]. A gap exists between what pre-service teachers are taught and the expectations placed on them for technology integration in their future classroom $[5,6]$. This gap leads to a disconnect between the skills they master and the perceived usefulness of these skills. This study examines how pre-service teachers perceive the technology use in the college classroom as it relates to Bloom's Revised Taxonomy.

The first step in examining education students' perception about technology is to understand how they are introduced to technology's potential role in the classroom. Pre-service teachers are introduced to the concept of technology integration through their own experiences as a student [7]. How future teachers experience technology integration is the pivot point on which they may base their perceptions of ability to effectively use technology in their own classroom [6].

DOI : 10.5121/ijma.2013.5501 
The International Journal of Multimedia \& Its Applications (IJMA) Vol.5, No.5, October 2013

Technology integration classes are required in teacher preparation programs but the content and pedagogy of the classes are program specific. According to the 2010 National Educational Technology Plan, technology should be an integral component of teaching methods courses and field experiences rather than treated as a discrete skill distinct from pedagogy.

While teaching methodologies vary from college to college and classroom to classroom, there does not seem to be a consensus of how technology should be modeled or integrated [8,9]. All teacher education students in the United States are required to take a basic technology course [10] however, pre-service teachers generally do not practice integrating technology within their methods classes [2, 11]. In a 2006 study of pre-service teachers and their learning experiences in an educational technology class, Brown and Warschauer found that most participants did not feel adequately prepared to enter a classroom and teach in a technologically rich environment. Similarly, other studies $[12,13]$ found that these required technology classes tended to focus on technology skills and not integration. This lack of emphasis on technology integration is made worse when many traditional teacher education programs also do not adequately model it in methods classes $[2,12,13]$.

While the past 30 years have brought an increased use of technology in many parts of society, the integration of technology into teaching methods and practices of pre-service teachers has not been fully realized [5]. Though technology has arrived in school districts throughout the US due to government sponsored grants and partnerships with corporations, this influx of technology into schools has led to challenges for colleges and institutions that prepare future teachers. Sixteen years ago, Hill and Summers [10] reported that Colleges of Education must be proactive in implementing teacher education programs that integrate technology through the entire teacher education, and that finding is still relevant today. Technology-integrated teacher education programs can be achieved by offering chances for pre-service teachers to observe modeling of technology by faculty and to practice using this technology in an encouraging atmosphere $[11,14$, 15]. Additionally, informed technology integration should occur in methods classes as well as by supervising teachers during practicum or student teaching experiences [4]. Given the enthusiastic call for technology integration within teacher education programs, one would expect to see recent teacher graduates who feel more secure integrating technology into their classrooms, but this is not the case as discussed below.

The Teachers Talk Tech survey [16] reported that $88 \%$ of teachers surveyed used technology only for administrative tasks, such as word processing or spreadsheets. In 2007, the Speak Up survey with over 23,000 respondents, reported that $93 \%$ of teachers surveyed used technology to connect with parents and coworkers [16]. Moreover, 51\% of the answering teachers detailed that their principal uses of technology to "facilitate student learning" involved either asking students to complete homework assignments using word processing on the computer or using drill and practice software. These findings form a pattern where teachers are using technology as an add-on rather than a systematic integration.

Most current teacher education graduates are likely to be confident using a range of technology tools $[4,17]$ and the federal government mandates; "to maintain their accreditation, teacher education programs are now required to include classes in the use of computers and other technologies" [10]. In order to produce future teachers that create learning environments rich with technology, a connection needs to be made between how we teach teacher education students and the way they perceive the role of technology in their future classrooms. One way to accomplish this is by applying Bloom's Revised Taxonomy. In 2001, a former student of Bloom's revised the taxonomy to reflect $21^{\text {st }}$ century thinking skills. The new terms are defined as: 
The International Journal of Multimedia \& Its Applications (IJMA) Vol.5, No.5, October 2013

- Remembering: Retrieving, recognizing, and recalling relevant knowledge from long-term memory.

- Understanding: Constructing meaning from oral, written, and graphic messages through interpreting, exemplifying, classifying, summarizing, inferring, comparing, and explaining.

- Applying: Carrying out or using a procedure through executing, or implementing.

- Analyzing: Breaking material into constituent parts, determining how the parts relate to one another and to an overall structure or purpose through differentiating, organizing, and attributing.

- Evaluating: Making judgments based on criteria and standards through checking and critiquing.

- Creating: Putting elements together to form a coherent or functional whole; reorganizing elements into a new pattern or structure through generating, planning, or producing. [18].

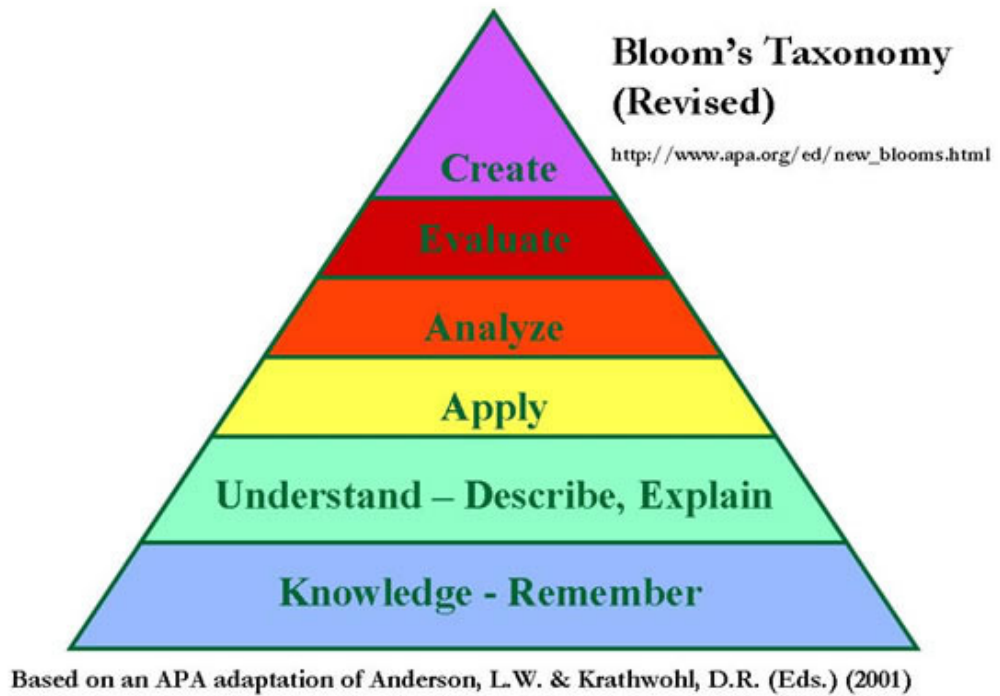

Figure 1: Bloom's Revised Taxonomy

The Revised Bloom's Taxonomy is broken into two dimensions: the knowledge dimension and the cognitive process dimension. Prior research into teacher education and technology integration has separately reported both knowledge and cognitive process information about the perceptions of teacher education students $[1,2,18]$. To make sense of the data presented in this study, we have separated the Revised Bloom's Taxonomy into three sections each containing both cognitive and knowledge information processes. By applying the Revised Bloom's Taxonomy [18] to teacher education student's perception of technology integration in their current programs, we will provide a description of the knowledge and cognitive processes that they experience as they complete their required technology integration classes.

Existing research addressing technology integration either focuses on the pre-service teacher program $[14,19,20]$ or the current use of technology in the classroom $[1,9,17]$. The latest advancement in integrating technology in teacher education, from online learning to iPads, has demonstrated a continuing need to better train pre-service teachers for teaching in technology rich environments. This study expands previous findings by outlining what occurs in the college classroom from the perspective of pre-service education students thus endeavoring to shed a new 
The International Journal of Multimedia \& Its Applications (IJMA) Vol.5, No.5, October 2013

light on technology practices from modeling to integration. This article addresses the perceptions of current teacher education students as they experience technology integration classes and connects these experiences to the Revised Bloom's Taxonomy [18].

\section{METHODS}

As with many qualitative studies, data analysis focuses on identification of key themes in the participants' responses. We paid attention to both the immediate and larger cultural context [21] while attempting to examine multiple layers of context and the different points of view of the participants involved. A qualitative methodology was used to explore the experiences of preservice teacher education students. In order to accomplish this, a phenomenological approach was used, which Johnson and Christensen (2008) note is meant, "to describe one or more individuals' experiences of a phenomenon" [22]. This required an in-depth interaction with the participants [22]. Moreover, this study incorporated two units of analysis: (1) the survey participants, and (2) the interview participants.

Participants were selected for their unique knowledge of the study focus: teacher education students currently attending a college or university in an accredited program. All participants completed the online survey and then a subsection was chosen for follow-up interviews on a random basis. This particular design allowed for both qualitative and quantitative approaches to the study development.

\subsection{Research Design}

The research design for this study was based on triangulation and expansion of data [22]. A survey was implemented that asked both quantitative and qualitative questions about classroom technology. After the survey round was complete, ten percent of participants were chosen at random for the interviews. This process was cyclical in which rounds of surveys were collected followed by interviews until no more participants were available for interviews.

A survey tool, Qualtrics ${ }^{\mathrm{TM}}$, was used to collect data over the Internet. Data was collected and analyzed for trends. After the survey data was collected, interviews were conducted with a random set of participants to gain a deeper understanding of their experiences. This study used a purposive sampling in order to identify and select those individuals in teacher education programs for the survey. Purposive sampling makes sense in this case because the research questions require participants with specific characteristics (Johnson \& Christensen, 2008). Student participants were identified by their enrollment in a teacher education class.

\subsection{Participants}

The general participants of the study were 656 education students enrolled at five colleges and universities from across the United States. The participants had an average age of 21 years and were over $70 \%$ female. Approximately $50 \%$ of the participants were studying elementary education and over $90 \%$ were full-time students attending classes during the day. All participants were taking, or had taken, the required technology integration course from their teacher education program. Within the general student participant set, ten percent of the students were chosen randomly as focus participants. The focus cases were used to confirm themes that arose during the broader survey collection. To accomplish this the focus participants participated in either online or in-person open-ended interviews. All of the participants were from a wide variety of colleges and universities that served a range of culturally, linguistically, and economically diverse student population. 
The International Journal of Multimedia \& Its Applications (IJMA) Vol.5, No.5, October 2013

\subsection{Data Collection}

The primary sources of data for this study were surveys, in-person interviews, and online interviews.

Surveys. A survey was created using the online program Qualtrics ${ }^{\mathrm{TM}}$. This survey was administered once to each participant set using an online system. Approximately $60 \%$ of the survey questions were derived from the Teaching, Learning, and Computing (TLC) National Survey of Schools and Teachers conducted by Dr. Henry Jay Becker and Dr. Ronald E. Anderson in 1998. The surveys assessed constructs such as the participants' teaching philosophy using technology, technology tool preferences, technology beliefs, use of technology in the classroom, and opportunities for technology growth. Likert scale; open-ended questions; and pick, group, and rank responses were included in both surveys. Each participant was emailed the link to the survey and connected through an anonymous server that assigned a random 10-digit alphanumeric code to each survey response. All surveys were administered over the Internet and average duration of activity was approximately 17 minutes.

In-person interviews. The researcher conducted one 30-minute interview with thirty of the preservice teacher participants over the course of five months. The individual interviews afforded a custom-made opportunity to explore and expand the story of each participant as they either learned about technology integration or used it in their own classroom. These open-ended interviews included questions about the participants' personal experiences using technology, their definition of technology integration, the ideal technology rich classroom, and their experiences in learning about technology integration. Most interviews were conducted at either a local restaurant or a local library. All interviews were conducted using a qualitative approach (Patton, 2002) and were audiotaped with permission from the participant. To elicit spontaneous interaction, the participants were encouraged to ask questions and pose answers in response to each of the 12 questions the researcher presented.

Online interviews. The researcher used online interviews to gather additional data from participants that could not, geographically or time wise, be interviewed in person. Thirty-five preservice teachers participated in online interviews. These interviews posed the same 12 openended questions, but were done asynchronously through a survey response system. The participants were emailed the link to the survey and encouraged to spend as much time as necessary explaining their answers fully. In cases where clarification was required follow-up questions were sent and received via email.

\subsection{Data Analysis Procedure}

As with many qualitative studies, data analysis focused on identification of key themes in the participants' responses. The researcher employed a primarily hermeneutic form of thematic analysis proceeded by data condensation [23] with additional techniques from phenomenology $[22,24]$. These processes aided in the organizing of data into meaningful 'bins' that became the basis for eventual themes. The process entailed the following steps: (1) reading of all survey answers and interview transcripts for an overall picture and looking for initial topics of relevance; (2) refining these preliminary topics through axial coding [22] into more formal themes within a thematic structure; (3) selecting demonstrative quotes from the transcripts and surveys to illustrate themes developed in step 2, while continuing to enhance the global thematic organization; (4) looking for connections between themes by comparing and contrasting them; (5) studying each as a part of the whole; (6) furthermore studying the whole as it relates to each theme; (7) scrutinizing the overall soundness of the thematic structure. These steps were fluid and 
The International Journal of Multimedia \& Its Applications (IJMA) Vol.5, No.5, October 2013

not followed in sequence, throughout the process several steps were performed concurrently and the researcher often backtracked to ensure overall consistency.

To achieve a more sizable and informative set of themes and assumptions, a type of cointerpretation was implemented where three members from a qualitative research class independently analyzed the data (using steps listed above). The team met five teams over the course of the study to debrief and discuss common threads that were appearing in the study. While the research team did not encounter any strong contradictions, there was a degree of negotiation on the first ten transcripts in order to develop a process that the whole group could agree upon. This process brought the group through the initial data analysis with few redundancies and many corresponding findings. One member of the research team integrated the four sets of themes into a single thematic structure and then solicited feedback from the group to create a more holistic view of the study findings.

\subsection{The Role of the Researcher}

The research team was composed of one doctoral-level professor in the field and two graduate students. The data analysis team was comprised of four graduate students in an advanced qualitative measures class at an academic institution under the guidance of a doctoral-level instructor. One of the researchers had been a classroom teacher for six years prior to the study and one was the head TA in an educational technology class that all pre-service teachers take at the university. Two of the researchers were trained in teacher education, one in evaluation, and three in qualitative research design.

To produce trustworthy results the researcher and analysis team utilized well-accepted qualitative standards designed to safeguard that the data was treated as legitimately as achievable [22]. Throughout the data collection and data analysis the research team used peer-debriefing, triangulation, member checking, progressive subjectivity check, and dependability audits.

\section{RESULTS}

The richness of this data set allowed the research team to identify a variety of potential themes. In order to prioritize all of the themes and find nesting themes, the team decided those that related most closely to the research questions should receive precedence. Themes that appeared most strongly supported, and appeared to have the most potential to shed new light on existing research, were selected to represent the study. Moreover, the research teams' interpretation of the data was justified based in that some themes that developed were in direct opposition to preconceptions. Illustrative quotes were chosen based on their clarity and representation of the themes established. In order to keep the responses as anonymous as possible the research team utilized pseudonyms and revised some quotes to create a smooth flow and ensure grammatical correctness. None of these changes altered the participants' meanings as suggested by member checks and ensured by dependability audits. Three themes regarding pre-service teacher views of technology and technology use were ultimately included. These themes were technology as a tool, technology as a process, and using technology to design curriculum. Each theme corresponds to a section of Blooms Revised Taxonomy.

\subsection{Theme 1: Pre-service teachers first identify and understand technology as a tool.}

From computers to Powerpoint ${ }^{\mathrm{TM}}$, and projectors to SmartBoards ${ }^{\mathrm{TM}}$, technology is most easily evaluated by pre-service teachers when it is concrete and given purpose within the classroom. Seeing technology as something touchable and purpose driven was how many participants 
defined technology integration. As participants intimated, technology as a tool can lend a legitimacy and depth to the subject area or work against the learning process all-together, depending on implementation.

Tools. Technology is judged by it's usefulness in the classroom, both as a value-add for student learning and as a pedagogical tool to increase effectiveness in teaching. It is a tool: a tool for teaching, a tool for learning, and a tool for intake of new information and disseminating new ideas. To quote some of the more strongly worded statements, technology is:

- 'a tool that assists teachers in instruction and students in learning.'

- 'some sort of electronic tool used for problem solving.'

- 'any tool that makes a task easier.'

- 'the ever-changing use of tools to help us meet our goals.'

With these comments, and many more about tools in mind, we set out to look at how technology and technology integration are focused on tools, not only the physical, but also their role in the mental processes that take place in the classroom. The first step in this process was to look at the Revised Bloom's Taxonomy [18] to evaluate participants' responses to technology as a tool.

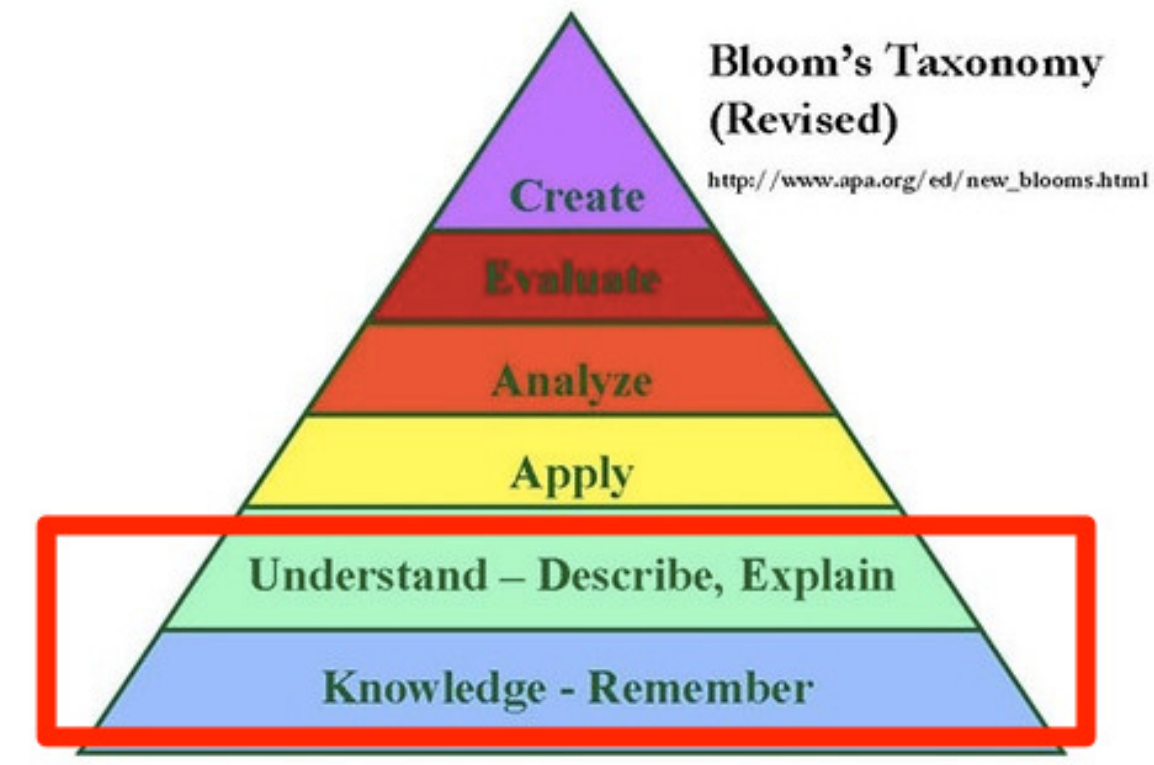

Based on an APA adaptation of Anderson, L.W. \& Krathwohl, D.R. (Eds.) (2001)

Figure 2: Revised Bloom's Taxonomy highlighting knowledge and understand.

\subsubsection{Knowledge and understanding.}

An interesting finding was that pre-service teachers define technology solely as a tool and integration as use of that tool in the classroom; their knowledge of what technology is has been formed by their experiences. One pre-service teacher stated that technology is "ever changing electronic tools which aid people with instant access to educational, entertainment and online services and resources," while another stated that technology is "any piece of equipment that allows for digital media/communication like computers, projectors, smart boards, etc." and still another commented that technology "involves tools which are used to serve a purpose." Preservice teachers also commented on technology integration, focusing on the use of tools in the 
The International Journal of Multimedia \& Its Applications (IJMA) Vol.5, No.5, October 2013

classroom to enhance knowledge of the tool. For example, "technology integration is coupling technology with education that is value added in the classroom. It requires hands on knowledge and practice to become experienced and provide technology-assisted education that is meaningful."

One secondary math student commented that technology integration is "incorporating technology into the classroom to better able students to learn the material through a variety of media sources. Technology integration means making this use of technology seamless during classroom lectures it also means that students should be able to interact and utilize the technology during class as well." While there were many definitions of technology integration from pre-service teachers the phrases that appeared most consistently were "using technology within a classroom effectively" and "integrating technological tools into classroom instruction." Technology and technology integration would theoretically go hand in hand, however through strength rating, the researcher has found that pre-service teachers see technology and the integration of that technology as tools and how those tools are utilized in a classroom.

Modeling of innovative technologies is demonstrated through specific instances in pre-service teacher education. Participants felt free to use whatever instances seemed most appropriate or helpful in a given situation during the interview process. This was never clearer than during the analysis and creation of this theme. While there was great consistency among the surveys and interviews for all of the themes, this theme in particular had participants that told the same story again and again, with little to no deviation. The research team felt that these occurrences strengthened the validity of our findings. The following two remarks illustrate this point perfectly. A pre-service teacher at a large university stated, "You know, I really don't see technology in action. I see presentations, I see demonstrations, but we don't ever get to use it. What am I supposed to do when I have my own class? If I teach like I have been taught then it will be a lot of lecturing." An in-service teacher, who had been teaching for six years at the time of this interview, stated, "I learned what not to do in my technology education class. I learned not to present. I learned not to demonstrate without having the students do something at the same time. I didn't know I was learning this until I had my own class and had to figure it through trial and error."

All pre-service teacher education programs are required to provide at least a class on computers and technology, but not all programs are created equally. There is no specific rubric or specific criteria for these programs, leading students to experience different levels of technology. Students may have technology integration in one class or on one day, but this study shows that it is not pervasive throughout their education classes. In-service teachers may pick and choose where to use technology in their classrooms, but this research has found that they are consistent in its use, whether working in a fully paperless classroom or having their students visiting the computer lab once a week [cite].

From the data collected in this study, the most common use of technology in a college teacher education classroom is PowerPoint ${ }^{\mathrm{TM}}$. Out of the 656 pre-service teachers surveyed for this study 648 of them reported that the tool most used in their education classes is PowerPoint with group work and problem solving coming in a distant second and third. Where do pre-service teachers see different technology being used? They see it in their required technology integration classes. One pre-service teacher stated, "the best use of technology I have experienced is the correct use of a document camera," while another said that the best use of technology demonstrated to her was "probably the Smartboard ${ }^{\mathrm{TM}}$. While it takes a little bit of getting used to because it is still relatively new, it is easily the most useful tool that any teacher could ever wish for."

Other technologies demonstrated in education classes include web 2.0 technologies, iPads, ELMOs, Skype, and Xtranormal cartoons. However in their regular teacher education classes, this 
integration of technology is lacking. One pre-service teacher commented that, "there is limited use, occasional video or power-point from the teacher. Students are encouraged to use technology creatively, but it is rarely modeled (perhaps because it's time consuming, or monetary resources are lacking)." While this seems to be the norm, it is not a ubiquitous situation; there are some pre-service teachers that have experienced technology integration in other classes.

"The best use of technology has probably been where the professor used all sorts of Web 2.0 tools to teach us or give out extra help. It went beyond simply telling us about the tools and showed us the practicality of them. A sort of 'walk the talk' approach made us more excited about the topics," stated one pre-service teacher. Modeling how to use technology in the classroom takes the use of that technology beyond tools and into pedagogy. One form of pedagogy that preservice teachers are exposed to with technology integration is through processes to create learning experiences.

\subsection{Theme 2: Pre-service teachers apply technology and analyze the process of integration.}

Participants shared their overall view of technology integration as a process to create learning. Identifying multiple ways in which technology is integrated into the classroom on a daily basis, the participants painted a detailed picture in which the teacher creates schedules, schema, and frameworks to utilize technology in an efficient way. Participants value technology in education. They did not talk about doing away with computers or creating spaces where technology is not welcome. Even participants that used little-to-no technology voiced the importance of it for students in the changing world. Their ability to link their prior experience of technology as a tool has led to a greater ability to apply and analyze technology integration as they prepare to use it in their own classrooms.

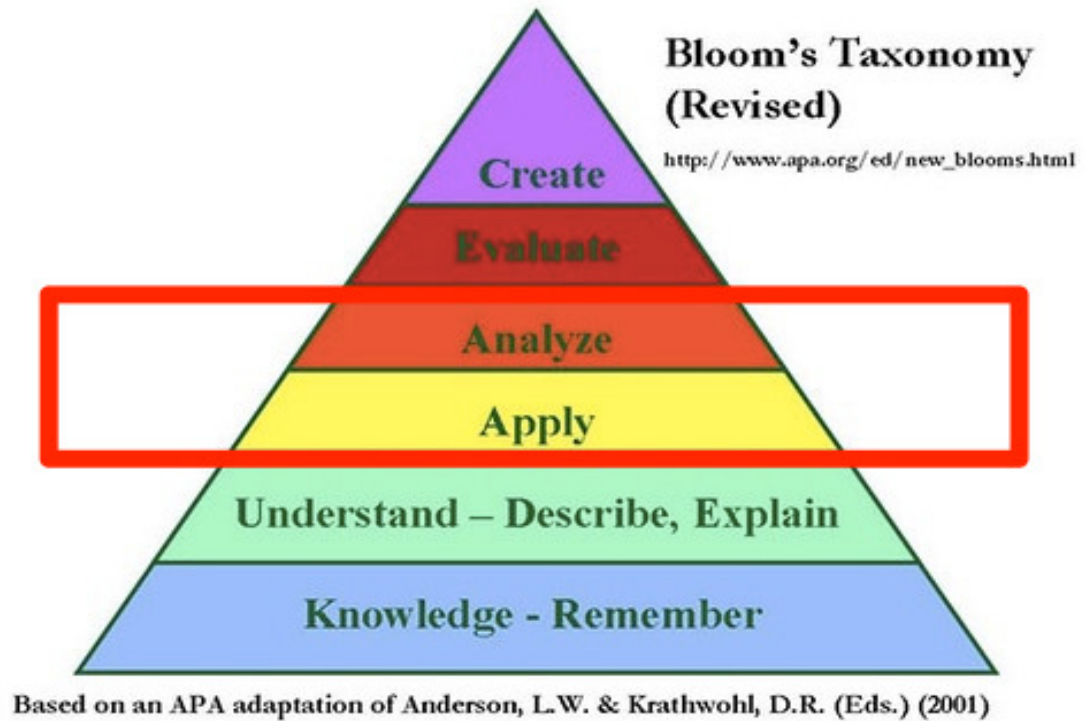

Figure 3: Revised Bloom's Taxonomy highlighting apply and analyze.

3.2.1 Apply. Pre-service teacher education students apply technology in controlled environments as either class projects or through group work where they research and present skills found to be useful in the classroom. "One thing I find useful in this class [technology integration class] is that we use the tools we will be using when we are teachers. On the other 
The International Journal of Multimedia \& Its Applications (IJMA) Vol.5, No.5, October 2013

hand, who knows if these programs will be at the school I get a job at," one third-year student commented during a follow-up interview. Each of the five universities where participants are enrolled has projects that teacher education students are required to complete as a part of their technology integration classes. Projects range from creating a large Powerpoint ${ }^{\mathrm{TM}}$ lesson and website creation to making blogs and wikis or working within virtual learning environments. Each of these applied projects are done on extended time frames (e.g, up to 9 weeks) within a classroom environment where the student is supported by either a teaching assistant or instructor. One first-year student commented, "It's good to get this practice but how realistic is it? Will I ever have this much time or support when I am teaching?" Other participants echoed this sentiment but were overall appreciative of the ability to practice technology skills within the technology integration class. Outside of the technology integration class is where the ability to apply and analyze technology integration fell apart.

Interview responses indicate that technology integration in the teacher education methodology class is fluid, but overwhelmingly stagnant, focusing on PowerPoint presentations presented with the teacher in front of the classroom and the students (e.g., pre-service teachers) sitting in lecture halls or classrooms. One of the most interesting findings that came out of this study came out of one question: What percentage of your class time are you being lectured to?

Pre-service teachers reported spending almost $70 \%$ of their time in classes listening to lectures. This demonstrates that there is a gap between how we teach teachers to teach and what actual teachers do when they teach. Modeling of technology, or walking the talk, is not being done in college classrooms but is being done overwhelmingly in the $\mathrm{K}-12$ sector. This is where application falls short.

\subsubsection{Analyze.}

The ability to look at a piece of information or technology and recognize its positives and pitfalls is a skill that most teacher education students have not experienced in-depth. In a follow up interview, a third year elementary education major stated, "We analyze our own learning and reflect on what we are doing as learners in most classes, but we don't ever really look at the technology part of it. If it worked [turned on and loaded] it was good and if it didn't it was bad." Survey results support this statement, with participants responding to a list of typical software and hardware (e.g., Prezi, Powerpoint ${ }^{\mathrm{TM}}$, Smartboards ${ }^{\mathrm{TM}}$, ELMOs) that they are not familiar with how it is best used in the classroom.

\subsection{Theme 3: Overall, pre-service teachers do not evaluate and create technology integration experiences}

Using technology to evaluate and create learning experiences within teacher education programs was notable in this study because of its relative absence within the survey and interviews. A minority of respondents briefly mentioned evaluation and creation of curricular activities. Every university had projects listed for creating lesson plans and curriculum units for their methodology classes, however the perceptions of the participants show that they do not recognize these projects as such. "One of my last methodology classes, I'm in it now, we look up materials from the Internet and make a book of curriculum resources for our student teaching. We also design lesson plans from this and are supposed to have technology resources for each lesson," a fourth year student stated. Other participants also listed similar experiences when talking about their teacher training classes, but did not naturally link creating curriculum binders with evaluating the technology within the lessons or creating curriculum with technology as its main mode of delivery. 


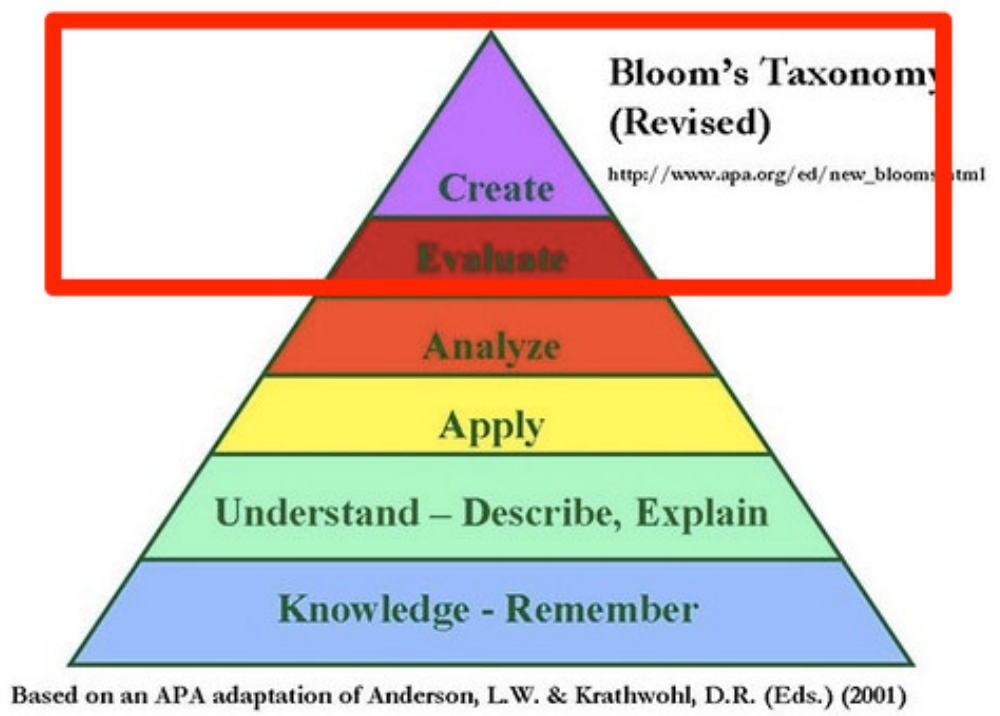

Figure 4: Revised Bloom's Taxonomy highlighting evaluate and create.

\subsubsection{Evaluate and create.}

As teacher education students move into their methods classes they use higher order thinking skills to evaluate current curriculum. "We see curriculum, like today we looked at Everyday Math, and have to assess how the learning will occur with students. But we don't do that with technology integration," a third year secondary math student commented. This was seen in other secondary majors as well. Students from secondary majors related that after gaining the conceptual and procedural knowledge required for daily practice, they learned about curriculum resources for specific subjects. However, within each of these specific methods, technology integration was not part of the curriculum evaluation. "For example, Houghton-Mifflin has web tools that we can use and access as teachers, but it's basically just about using it and not about knowing how it works," stated a second year English education major. As students assess curriculum they are asked to draw conclusions about the learning goals and benchmarks associated with the content. Teacher education students did not see evaluation of technology or its integration within the curriculum as a main activity in the class.

Teacher education students start to create lesson plans and curriculum resources as they progress through the teacher education program. Within their technology integration classes teacher education students are asked to not only evaluate technology, but to create lessons where it is integrated as a part of the learning outcomes. "In [class name] we made three different lessons where students use a certain technology to learn about different things, but that is the only class where we got to do that," stated a second year elementary education major. As students put together their teaching portfolios they are asked to use various modes in order to document their learning. From binders full of paper to sleek e-portfolios, students create this project using everything from pictures to interactive video. None of these skills are taught within the methods classes they are required for. "One part of our final assignment was to videotape ourselves teaching using Flip Cameras, import the video onto a computer and edit it to show only five minutes. This had to be complete with titles and then exported in a certain format. No one showed us how to do any of that, we were told to go to the technology lab to get help," commented a fourth year secondary science major. She went on to add, "This would be the kind of thing I could 
have my students do for experiments if we had done it during the methods section, rather than in my student teaching."

The scaffolding of technology use with teacher education students through their prescribed programs is not seen as systematic among the participants. In order to actualize curriculum resources, teacher education students conduct searches for materials that fit best into their lessons and will be a value-add for their students. This composing of resources for teaching allows teacher education students to create banks of classroom materials for their future positions. However, this process has not kept pace with the technology available today, hindering teacher education students from fully utilizing what technology they are familiar with. One secondary chemistry major commented, "I use Twitter and Facebook, I have a Diigo account and a Wordpress blog but I can't use any of these things to create my [curriculum book]. I have to print out everything and put it in a binder to hand in and I probably won't keep it for my classroom." Creating curriculum resources is happening in teacher education, however the use of technology to produce these resources is not a systematic process.

\section{DisCuSSION AND CONCLUSIONS}

This study shed some light on pre-service teacher views and reported uses of technology in the college classroom. Participants reported that they value and plan to use technology in their future classrooms. Moreover, participants reported that technology is available to them as a means of tools, process, and design.

This study revealed that although there is a basic course all teacher education students are required to take on technology, it does not necessarily prepare them to integrate it into their teaching practices. There is no standardized technology integration standard that teacher education institutes need to meet as long as they have a course that addresses technology. This leads to some teachers, as demonstrated here, leaving college with exemplary experiences of what it means to integrate technology and some without any knowledge more powerful then a PowerPoint.

This study supports the view that many pre-service teachers feel they may not be adequately prepared to teach with technology. Improvements may need to be made in how pre-service teachers are taught to use technology in the classroom. Based on the findings of the current study, such improvements may include (1) technology integration into methods courses, (2) revision of technology courses to include an application component, and (3) increased collaboration between $\mathrm{K}-12$ districts and schools of education.

Teacher education programs may create instances where students can see good modeling of technology integration and learn practices to replicate them [6]. Providing technology experiences in all classes, and not just the required technology course [10] above and beyond PowerPoint presentations may create technology-enriched instruction. Contextualized, collaborative learning environments that support curriculum content may be achieved by modeling technology integration within methods courses $[6,11,19]$

Pre-service teachers need to use technology systemically and not just learn about technology use in a single class [10]. To build confident technology users and enhance student learning an application of technology may be adopted by all programs. Consequently it seems to suggest that simply learning how to make a PowerPoint or write a lesson plan in Word does not teach how to implement these tools within a learning context. The current study found that of the five teacher education institutes surveyed they all had different standards for their students when it came to applying technology in the classroom. While not a representation of teacher education nationally 
it is representative of a variety of programs across the country in rural, suburban, and urban areas servicing a diverse group of students.

Teacher education institutions and school districts should cooperate in designing curriculum for the pre-service teachers $[13,25,26]$. This collaboration would serve two needs simultaneously; (1) pre-service teachers would be taught how they are going to teach (e.g. modeling), and (2) districts could have pre-service teachers work on technology projects that teachers would actually use to teach. Including university faculty into this process allows current teachers to increase their knowledge of technology and pedagogy and at the same time demonstrates to the university faculty how teachers are using technology in their classrooms. By creating a model where university faculty work with in-service teachers who in turn mentor pre-service teachers currently still in the university classroom a cycle would be started to constantly renew teaching practices and integrate technology comprehensively.

\subsection{Limitations and Future Research}

In as much as the focus of this research was on how technology is used, it was also based on the perceptions of technology integration in the college classroom and not documented accounts. Accordingly, future research may benefit from exploration of how teachers experienced technology prior to their teaching careers and what affect that has had on their use of technology in the classroom.

Another limitation involves the inquiry method the research team employed. The research team did not have experience with every technology tool or program that the participants did and had to use inferences to create understanding among the responses. Because of this opacity in the levels of practice and experience it makes it difficult to adequately characterize answers into themes. To see more clearly, future research will have to look beyond survey questions and reflective interviews to other methods, perhaps observations to create a clearer picture.

\section{ACKNOWLEDGEMENTS}

The authors would like to thank the teacher education students who took part in this study.

\section{REFERENCES}

[1] Ertmer, P. (2005). "Teacher pedagogical beliefs: the final frontier in our quest for technology integration?" Educational Technology Research and Development 53(4): 25-39.

[2] Ottenbreit-Leftwich, A. T., Brush, T. A., Strycker, J., Gronseth, S., Roman, T., Abaci, S., ... \& Plucker, J. (2012). Preparation versus practice: How do teacher education programs and practicing teachers align in their use of technology to support teaching and learning?. Computers \& Education, 59(2), 399-411.

[3] Koehler, M. and P. Mishra (2009). "What is technological pedagogical content knowledge." Contemporary Issues in Technology and Teacher Education 9(1):60-70.

[4] Ertmer, P.A., \& Ottenbreit-Leftwich, A. (2010). Teacher Technology Change: How Knowledge, Confidence, Beliefs, and Culture Intersect. Journal of Research in Technology in Education, 42(3), 255-284.

[5] Pope, M., Hare, D., \& Howard, E. (2002). Technology integration: Closing the gap between what preserivce teacher are taught to do and what they can do. Journal of Technology and Teacher Education,10(2), 191-203.

[6] Stobaugh, R. R. \& Tassell, J. L. (2011). Analyzing the degree of technology use occurring in preservice teacher education. Educational Assessment, Evaluation, and Accountability, 23, 144-157.

[7] Lortie, D. C. (1975). Schoolteacher: A sociological study (pp. 25-81). Chicago: University of Chicago Press. 
The International Journal of Multimedia \& Its Applications (IJMA) Vol.5, No.5, October 2013

[8] Borko, H., Whitcomb, J., \& Liston, D. (2009). Wicked problems and other thoughts on issues of technology and teacher learning. Journal of Teacher Education, 60(1), 3-7.

[9] Pierson, M. (2001). "Technology integration practice as a function of pedagogical expertise." Journal of Research on Computing in Education 33(4): 413-430.

[10] Bureau of Labor Statistics, U.S. Department of Labor, Occupational Outlook Handbook, 2010-11 Edition, Teachers-Kindergarten, Elementary, Middle, and Secondary, on the Internet at http://www.bls.gov/oco/ocos318.htm (visited March 27, 2011).

[11] Albion, P., \& Ertmer, P. A. (2002). Beyond the foundations: The role of vision and belief in teachers' preparation for integration of technology. TechTrends, 46(5), 34-38.

[12] Adamy, P. \& Boulmetis, J. (2006). The impact of modeling technology integration on pre-service teachers' technology confidence. Journal of Computing in Higher Education, 17(2), 100-120

[13] Best, L.M. (2002). Comparison of the perceptions of university faculty and preservice students' technology skills and integration of technology in selected elementary education courses (Doctoral dissertation, Indiana University of Pennsylvania, 2002) Dissertation Services, 3045741.

[14] Ertmer, P. A., Ottenbreit-Leftwich, A., \& York, C. (2006). Exemplary technology-using teachers: Perceptions of factors influencing success. Journal of Computing in Teacher Education, 23(2), 5561.

[15] Zhao, Y., \& Cziko, G. A. (2001). Teacher adoption of technology: A perceptual control theory perspective. Journal of Technology and Teacher Education, 9, 5-30.

[16] CDW-G. (2006). Teachers Talk Tech reveals technology access and professional development are driving improved teacher and student performance. Retrieved September 8, 2011, from http://newsroom.cdwg.com/news-releases/news-release-06-26-06.html

[17] Staples, A., M. Pugach, et al. (2005). "Rethinking the Technology Integration Challenge: Cases from Three Urban Elementary Schools." Journal of research on Technology in Education 37(3): 285-312.

[18] Anderson, L. W., \& Krathwohl, D. R. (Eds.). (2001). A taxonomy for learning, teaching and assessing: A revision of Bloom's Taxonomy of educational objectives: Complete edition, New York : Longman.

[19] Brown, D., \& Warschauer, M. (2006). From the university to the elementary classroom: Students' experiences in learning to integrate technology in instruction. Journal of Technology and Teacher Education, 14, 599-621.

[20] Brown, S. (2003). The effects of technology on effective teaching and student learning: A design paradigm for teaher professional development. Retrieved September 2, 2011, from http://www.waukeganschool.org/TechPlan/ResearchFindings.pdf

[21] Johnson, B. \& Christensen, L. (2008). Educational research: Quantitative, qualitative, and mixed approaches (3rd ed.). Thousand Oaks, CA: Sage Publications, Inc.

[22] Patton, M. Q. (2002). Qualitative Research and Evaluation Methods. Thousand Oaks, Sage Publications.

[23] Fleming, V., Giadys, U., \& Robb, Y. (2003) Hermeneutic research in nursing: Developing a Gadamerian-based research method. Nursing Inquiry, 10, 113-120

[24] Giorgi, A.P., \& Giorgi, B.M. (2003) The descriptive phenomenological psychological method. In P.M Camic, J.E. Rhodes, \& L. Yardley (Eds.) Qualitative research in psychology: Expanding perspectives in methodology and design (pp. 243-273). Washington DC: American Psychological Association.

[25] Bauer, J. and J. Kenton (2005). "Toward technology integration in the schools: Why it isn't happening." Journal of Technology and Teacher Education 13(4): 519.

[26] Carlson, R. D. and J. S. Gooden (1999). "Mentoring pre-service teachers for technology skills acquisition." TECHNOLOGY AND TEACHER EDUCATION ANNUAL 2: 1313-1318. 
The International Journal of Multimedia \& Its Applications (IJMA) Vol.5, No.5, October 2013

\section{AUTHORS}

Dana Ruggiero is a Senior Lecturer in Learning Technology in the School of Education at Bath Spa University. Her research interest focuses on praxis in design for persuasive technology, including the application of games for social issues.

Christopher Mong is a PhD graduate of Learning Design and Technology at Purdue University. His research interest is focused on problem based learning and teacher training.
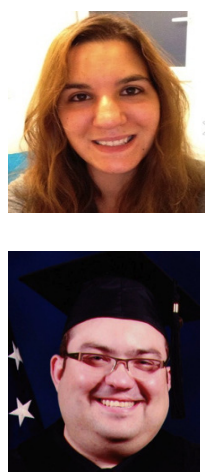